\title{
Can the rising pension burden in Europe be mitigated by immigration? Modelling the effects of selected demographic and socio- economic factors on ageing in the European Union, 2008-2050
}

\author{
Fernando Gil Alonso*
}

\begin{abstract}
Demographic change, and more specifically ageing - defined here as the increase in the numbers of retired people - is one of the main challenges which European societies must face. Although this challenge cannot be reduced to the demographic factor alone, the construction of highly sophisticated models to analyse the social and economic impact of ageing introduces problems of data availability and comparability between EU Member States. The approach used in this paper to overcome these obstacles is different. A demography-based model (inspired by Gérard Calot's previous work) which uses some simplified assumptions, has been defined to assess the implications of ageing for the $27 \mathrm{EU}$ countries over the period 2008-2050, and the relative impact of a series of alternative measures which could be implemented to counteract ageing. Though the analysis will focus on labour supply growth through foreign (extra-EU) immigration, other actions like the increase of the average effective age at which the labour market is left or employment rate growth will also be taken into account. Results show that immigration by itself cannot counteract ageing in the European Union as the number of immigrants needed to compensate for the increasing number of retired people would be so high that no country could assume the social and political costs of such a process. However, it can play a complementary role if it is combined with other measures contributing to both increase labour participation and delay retirement. This policy mix should be
\end{abstract}

* Fernando Gil Alonso, Geografia Humana, Universitat de Barcelona, c. Montalegre, 6, 08001 Barcelona, Spain. Email: fgil@ub.edu

This research has been elaborated in the framework of the R+D Project CSO2008-06217/SOCI, directed by Dr. Fernando Gil and funded by the Spanish Ministry of Science and Innovation, through the National $R+D+I$ Plan 2008-2011. 
different in each EU Member State depending on the initial specific situation of each parameter of the model.

\section{Introduction: The need for a simplified model to ensure sufficient comparability between countries}

Demographic projections indicate that European population ageing will become more pronounced over the next decades. This demographic trend will have economic and social consequences in a number of areas with important policy implications (European Commission 2009; OECD 2007a). For instance, population ageing has raised a lot of interest among policymakers working in the field of pensions, and particularly in relation to the future sustainability of pension systems across the European Union and other developed countries (OECD 2009b). As most of the European public pension schemes are pay-as-you-go (PAYG) systems where today's workers pay the pension of today's retired people (Whitehouse 2007; OECD 2007b, 2009a), the future decrease in the working age population and increasing numbers of retired people are supposed to threaten the equilibrium of pension systems. Concerns over the increasing costs of health systems and the future productivity of the European economy have also been expressed.

An important indicator of the ageing process, particularly related to the sustainability of pension systems, is the ratio of the number of retired to the number of employed people. This is often referred to as the economic dependency ratio (EDR). At the European Union level, the pressure on the economic dependency ratio will increase after 2010 as the baby boom generation will start entering the retirement age. Consequently, the EDR will probably keep increasing until about 2040, all other factors being constant. The pressure of the baby boom effect on the dependency ratio will then start decreasing. Only an important growth of the working age population due to an increase in fertility levels or, more likely, a continuous inflow of (young) immigrants could help compensate for the tendency to ageing.

However, the analysis of the economic implications of ageing (e.g. on the financial sustainability of pension systems) cannot only be limited to the effect of demographic factors. It also needs to take into account other factors that play a major role in funding pensions, such as the employment level, the economic performance in terms of productivity (GDP per employed person), and the main characteristics of the pension systems in relation to the level of contributions and the relative level of pensions.

A considerable amount of research has already been devoted to examine the economic consequences of ageing (see for instance: Lee et al. 2001; Lesthaeghe 2002; Mason 2005); including its impact on the labour market (Coleman 1992, 2004; Feld 2000; Fotakis and Gil Alonso 2002; Bijak et al. 2007), human capital 
and productivity (Skirbekk 2004; Lutz et al. 2004; OECD 2006; Prskawetz 2005; Prskawetz et al. 2008), health/disability (Lutz and Scherbov 2005), care of older people (Murphy et al. 2006; Gaymu et al. 2007), and the sustainability of pension systems (Franco and Munzi 1996; Fotakis 2000; European Commission 2006; OECD 2007b and 2009b). In the majority of the European Union Member States, there already are many sophisticated models for forecasting pensions which take due account of the specificities of national pension systems. Nevertheless, it is very difficult to draw comparisons between countries due to the differences in the models used, particularly in terms of their structures and basic assumptions and of course the different types of pension systems that exist across EU countries. Several attempts have also been made in the past, based on the analytical models and projections used in several countries (see for instance Franco and Munzi 1996; European Commission 1997), to provide a common framework at European level. However, their complexity and lack of comparability among countries limit the use of their results.

A suggestive way to overcome this obstacle, used in this paper, is by defining a model that uses simplified assumptions. It does not intend to give precise pension expenditure forecasts, but rather assesses the demographic effect of ageing on the balance between contributions and benefits, keeping all other factors unchanged. At the same time, the model sheds light on the implications of a range of economic and demographic measures-increasing international immigration among them - that could be used to reduce the ageing burden.

\section{Presentation of the broad framework of the model}

The model presented in this paper improves, updates (using the new 2008-based 'convergence' scenario of the Eurostat population projections) and extends up to 2050 and for the current 27 Member States the old one developed for the European Commission in the internal working paper "Pension Sustainability, Ageing and Labour Supply"1 (Gil Alonso and Math 2000). That model was applied to the then 15 Member States and was developed, at a macro-economic level, on the basis of the previous one proposed by Calot et al. (1995). A later unpublished version of the model presented at the IUSSP International Population Conference 2005 in Tours was enlarged to include 25 EU countries (Gil Alonso 2005). All these models integrate the necessary key elements to assess pension funding sustainability and are based on the same principle: a PAYG system is in an equilibrium situation when there is a balance between the total contributions to pensions and the total benefits received by retired people. If the number of retirees increases due to ageing, the volume of pensions will increase and the system will be put into difficulties unless the other variables of the model change

That paper was written by the author together with the key contribution of Antoine Math and the collaboration of Costas Fotakis, Edit Corominas and James Battye. 
to recover the initial financial equilibrium. These variables are: the number of (indigenous or immigrant) people in employment, the average exit age from the labour market, the so-called 'transfer ratio' and the proportion of GDP spent on pensions. It is a somewhat more complex model than the purely demographic one proposed by United Nations (2001) in its famous publication on 'replacement migrations', where the only variable compensating a declining and ageing population was an increase in the number of immigrants. ${ }^{3}$

The present model uses Eurostat demographic projections (convergence scenario) for the period 2008-2050 to foresee the future evolution of retired people. This is the model's initial input. The implications of ageing on the balance between contributions and benefits (keeping all other factors unchanged) are examined, as well as the change(s) required in other key parameters of the model to ensure equilibrium between the total contributions to pensions and the total benefits received during the analysed period. In this way, the model provides an insight on how the implications of ageing may be mitigated when examining possible evolutions of other key factors such as: increasing the effective retirement age (which primarily leads to a lower number of retirees and therefore to less pension expenditure, and may secondarily increase the number of employed people and consequently the total contributions); decreasing the pension levels (and thus the expenditure); increasing the number of people in work - either through immigration or growing employment rates - and their productivity (which both imply an increase in the total contributions); and finally increasing their average contributions to the pension system. These alternative compensatory measures are the outputs of the model. Among these, the number of employed immigrants required to enter after 2008 (plus their employed children born since) to compensate for the increasing size of the retired population will be emphasised in this paper.

2 There, "replacement migration" was defined in several ways, depending on the scenario: as the number of foreign immigrants required to maintain the size of the total population at the highest level it would reach in the absence of migration after 1995; as the migration required to maintain the size of the working-age population (15-64 years) at the highest level it would reach in the absence of migration after 1995; as the migration required to prevent the ratio of the population aged 15-64 to the population aged $65+$, called the potential support ratio (PSR), from declining below the 3.0 level; and as the migration required to maintain the PSR at the highest level it would reach in the absence of migration after 1995.

3 I would like to highlight the following UN replacement migration model major findings, as they coincide with some of the results of my own research: "The levels of migration needed to offset population ageing (i.e., maintain potential support ratios) are extremely high, and in all cases entail vastly more immigration than has occurred in the past", and "maintaining potential support ratios at current levels through replacement migration alone seems out of reach, because of the extraordinary large numbers of migrants that would be required" (United Nations 2001: 4). 


\section{Formal description of the model}

At the macroeconomic level, the funding of pensions is a question of Gross Domestic Product (GDP) redistribution from those who are participating in economic life to those who are already retired. A pension system can be described as in equilibrium when the volume of contributions levied on workers equals the amount of pensions paid to retired people.

$$
\text { Volume of contributions }=\text { volume of pensions }
$$

or

$$
\mathrm{GDP} \cdot \mathrm{c}=\mathrm{R} \cdot \mathrm{p}
$$

where

- $\quad$ GDP $=$ the wealth produced (gross domestic product)

- $\quad \mathbf{c}=$ the share of gross domestic product necessary to finance pensions, comprising all forms of contribution to the system, i.e. employers and employees contributions, taxes and other contributions ${ }^{4}$

- $\quad \mathbf{R}=$ the number of retired people

- $\quad \mathbf{p}=$ the average pension

(2) is equivalent to:

$$
\mathrm{E} \cdot \mathrm{GDP} / \mathrm{E} \cdot \mathrm{c}=\mathrm{R} \cdot \mathrm{t} \cdot \mathrm{GDP} / \mathrm{E}
$$

where:

- $\quad \mathbf{E}=$ the number of people in employment (in full-time equivalents), i.e. the people producing the GDP from which the pensions are financed

- $\mathbf{G D P} / \mathbf{E}=$ the average gross domestic product per employed person (GDP divided by the number of people working)

- $\quad \mathbf{t}=$ the 'transfer ratio', defined here as the ratio of average pension to average gross domestic product per employed person $(t=p /(G D P / E))$

(3) can be simplified further and then is equivalent to:

$$
\mathrm{E} \cdot \mathrm{c}=\mathrm{R} \cdot \mathrm{t}
$$

As the number of retired people (R), the number of employed people (E) and the weight of contributions in percentage of GDP (c) is known for any particular year, $t$ can be estimated for 2008 (initial year of the projection model) by assuming the equilibrium between expenditure and receipts.

$$
\mathrm{t}=\mathrm{E} / \mathrm{R} \cdot \mathrm{c}
$$

In this model, pension sustainability is achieved when total resources equal total expenditure at the macroeconomic level during the considered period (in this

\footnotetext{
This broad definition of "c" is resulting from the underlying assumption that people in employment are the only producers and contributors within the system and hence there is no difference between systems financed more through taxation and systems financed more through social contributions.
} 
case, 2008-2050). Within this framework, it is not relevant whether pension schemes are based on a pay-as-you-go (PAYG) system or are funded schemes. ${ }^{5}$

\section{Assumptions for the variables and parameters used in the model}

The model works under the basis of the following assumptions:

- Pension schemes are assumed to be in financial equilibrium in the starting year (2008). Therefore, all findings should be related to this year as the reference point.

- The only external shock unbalancing the system is assumed to be the change in the number of retired people (defined as the number of persons aged over the average labour market exit age in each country) due to population ageing.

- Data on population by age for the period 2008-2050 are taken from Eurostat demographic scenarios (convergence scenario). The methodology of this projection is based on the assumption that the socio-economic and cultural differences between the Member States of the European Union (EU) will fade out in the very long run (in this case, by the year 2150). If these narrowing differences concern the demographic drivers, then the assumption implies that demographic values are convergent. Two different convergence scenarios have been developed by Eurostat: with migration and without migration from 2009 onwards (therefore population growth and structure is only determined by births and deaths). The latter has been preferably used here, as the number of (employed) immigrants (and their descendants) compensating ageing is one of the main outputs of the model. However, the more realistic scenario with migration has also been used to compare results and to assess the compensatory effect of migration levels forecast by Eurostat.

- $\mathbf{E}$, the number of people employed and therefore contributing to the system, is calculated by using the full-time equivalents (FTE). They have been calculated for each country by multiplying the number of people working parttime times the ratio of the average number of usual weekly hours of work of those working part-time to the average number of usual weekly working hours of fulltime employees. This ratio is around 0.5 , but significant variations exist among countries. The resulting figures, plus the number of people currently working fulltime, give us the total number of full-time equivalent employees. Taking the FTE rate provides a better and more comparable insight, between countries and over

5 The problem of GDP redistribution at macro level between those working and those who are retired is the same for PAYG and funded schemes, since the current GDP is shared every year between those who receive income directly from their participation in economic life and those who do not. If there are more elderly retired people, the share of pensions in GDP is likely to be greater, whatever the funding base of the pensions, contributions, taxes or financial yields. 
time, of the ability of employed people to create wealth and to contribute to pension systems funding. ${ }^{6}$

- c , the share of GDP levied to finance pensions, is estimated from the total expenditure on old age and survivors' benefits, as given by Eurostat ESSPROS database. $^{7}$

- $\mathbf{R}$, the retired population, is assumed to be the part of the population above the average effective retirement age (ERA, as defined by Eurostat: average exit age from the labour market, weighted by the probability of withdrawal from the labour market). This assumption is acceptable as most older people actually have direct or derivative rights to pensions. The average effective retirement age has been estimated for each country by Eurostat (see the indicator called "average exit age from the labour force, weighted by the probability of withdrawal from the labour market") from EU Labour Force Survey data on age-specific activity rates.

- t the transfer ratio, is equal to $\mathbf{E} / \mathbf{R} \cdot \mathbf{c}$ when the system is in equilibrium (see Equation 5) and provides a proxy measure to assess the evolution of the relative pension level. It is similar to the 'net replacement rate' used in other models, which is the ratio of the average pension to the average wage. However, ' $t$ ' puts in relation the average pension to the average GDP per employed person, which is a direct measure of productivity - indeed, ' $t$ ' can decrease because the average pension diminishes or because productivity increases. Therefore, maintaining the relative level of average pension implies that the absolute level of the average pension should evolve at the same pace as productivity.

- As the model assumes that GDP is entirely produced by employed people and pensions are distributed among the retired population (as defined in R), it disregards people who are neither employed nor retired. It is hence assumed that those people are neither contributing nor costing anything to GDP, although some of them may benefit from different forms of government transfers-and unemployed people impose opportunity costs, by reducing contributions to the pension system. This assumption of this simplified model is obviously fully justified as the paper's main interests are the consequences of ageing on old age (retirement and survivors) pensions. A more complex model could incorporate the impact of other forms of government transfers and social policies-e.g. health

6 Part-time workers contribute less than full time ones regardless the type of pension system funding: directly through social contributions (since those are mostly more or less proportional to earnings), or indirectly through general taxation. Furthermore, using FTE allows for a more reliable comparison between countries, given the wide dispersion of the prevalence and average duration of part-time employment within the European Union.

7 The ESSPROS (European System of Social Protection Statistics) database on social protection expenditure and receipts has been compiled by Eurostat on a new system of classification since 1997. The database is designed to provide a comparable indication of the scale of expenditure and receipts in different EU countries, as well as of developments over time. At present it is the most reliable and harmonised data source on social protection in the European Union, although some comparison problems between Member States still remain. 
care contributions and expenditure, which are distributed across ages in a similar way as pensions, or unemployment benefits.

The values of the parameters of the model in 2008 (or more recent available data) for the 27 Member States, as well as for EU-15 and EU-25, can be seen in Table 1. This table also shows the figures for related indicators such as the economic dependency ratio, the full-time equivalent employment rate and the average effective retirement age-which is significantly lower than the 'legal' retirement age in most countries. Table 1 shows a wide range of 2008 'starting' positions in the different parameters:

- Parameter ' $c$ ', which has remained quite stable in the EU at around $12 \%$ in the last years, varies widely between countries, from just $4.6 \%$ in Ireland and around $5.7 \%$ in the Baltic countries to $13.5 \%$ in Belgium and $15.5 \%$ in Italy.

- The transfer ratio is significantly below the European average in Lithuania, Estonia and Latvia, and relatively high in Sweden, the Netherlands, Cyprus and Austria.

- The lowest economic dependency ratio can be found in Ireland (27.1\%) and the highest in Italy (69.7\%), well above the EU-27 average (52.4\%).

- Full-time equivalent employment rates vary between the minimum values found in Malta $(51.6 \%)$ and Poland $(53.6 \%)$ and the highest ones in Latvia (69.2\%), Estonia (69.1\%), Denmark (68.1\%) and Sweden (68\%)-EU average around $61 \%$.

- Finally, in Romania, Bulgaria and Ireland the average effective retirement age is already above 64 years (followed by Sweden and the Netherlands at 63.9), whereas in Malta and Slovakia it is just below 59, followed by France and Luxembourg. 
Table 1:

Main parameters of the model in 2008 (or more recent available data) in the EU Member States and in the whole EU

\begin{tabular}{|c|c|c|c|c|c|c|c|c|}
\hline & \begin{tabular}{|c}
$\mathrm{R}$ (In \\
retirement age, \\
thousands)
\end{tabular} & $\begin{array}{c}\text { E (Employed, } \\
\text { thousands) }\end{array}$ & $c(\%)$ & $\mathrm{t}$ & EDR & ER & ERA & $\begin{array}{l}\text { wap (Working } \\
\text { age pop., } \\
\text { thousands) } \\
\end{array}$ \\
\hline Belgium & 2,217 & 3,959 & 13.5 & 0.24 & 56.0 & 56.2 & 61.6 & 7,039 \\
\hline Bulgaria & 1,409 & 3,222 & 7.7 & 0.18 & 43.7 & 60.9 & 64.1 & 5,295 \\
\hline Czech Republic & 2,104 & 4,799 & 7.8 & 0.18 & 43.8 & 65.2 & 60.7 & 7,355 \\
\hline Denmark & 1,182 & 2,461 & 10.7 & 0.22 & 48.1 & 68.1 & 60.6 & 3,613 \\
\hline Germany & 19,034 & 32,493 & 12.2 & 0.21 & 58.6 & 59.7 & 62.0 & 54,415 \\
\hline Estonia & 262 & 629 & 5.6 & 0.13 & 41.6 & 69.1 & 62.5 & 910 \\
\hline Greece & 2,596 & 4,368 & 12.1 & 0.20 & 59.4 & 58.0 & 61.0 & 7,525 \\
\hline Spain & 8,865 & 19,045 & 8.4 & 0.18 & 46.5 & 61.2 & 62.1 & 31,143 \\
\hline France & 14,001 & 23,733 & 12.9 & 0.22 & 59.0 & 58.9 & 59.4 & 40,324 \\
\hline Ireland & 529 & 1,955 & 4.6 & 0.17 & 27.1 & 64.7 & 64.1 & 3,026 \\
\hline Italy & 15,101 & 21,674 & 15.5 & 0.22 & 69.7 & 55.2 & 60.4 & 39,230 \\
\hline Cyprus & 110 & 362 & 8.3 & 0.27 & 30.3 & 65.1 & 63.5 & 557 \\
\hline Latvia & 430 & 1,083 & 5.7 & 0.14 & 39.7 & 69.2 & 63.3 & 1,566 \\
\hline Lithuania & 695 & 1,476 & 5.7 & 0.12 & 47.1 & 63.7 & 59.9 & 2,316 \\
\hline Luxembourg & 95 & 187 & 7.3 & 0.14 & 50.6 & 57.3 & 59.4 & 326 \\
\hline Hungary & 2,223 & 3,858 & 9.2 & 0.16 & 57.6 & 55.8 & 59.8 & 6,913 \\
\hline Malta & 93 & 148 & 9.4 & 0.15 & 63.0 & 51.6 & 58.5 & 287 \\
\hline Netherlands & 2,634 & 6,361 & 11.4 & 0.27 & 41.4 & 57.5 & 63.9 & 11,055 \\
\hline Austria & 1,791 & 3,528 & 13.4 & 0.26 & 50.8 & 62.7 & 60.9 & 5,628 \\
\hline Poland & 7,256 & 14,526 & 11.5 & 0.23 & 49.9 & 53.6 & 59.3 & 27,083 \\
\hline Portugal & 2,129 & 4,780 & 11.7 & 0.26 & 44.5 & 67.0 & 62.6 & 7,139 \\
\hline Romania & 3,333 & 9,013 & 6.2 & 0.17 & 37.0 & 60.2 & 64.3 & 14,969 \\
\hline Slovenia & 433 & 931 & 10.1 & 0.22 & 46.5 & 65.7 & 59.8 & 1,416 \\
\hline Slovakia & 995 & 2,328 & 6.9 & 0.16 & 42.8 & 59.7 & 58.7 & 3,901 \\
\hline Finland & 1,113 & 2,313 & 9.6 & 0.20 & 48.1 & 65.5 & 61.6 & 3,530 \\
\hline Sweden & 1,745 & 4,104 & 12.1 & 0.28 & 42.5 & 68.0 & 63.9 & 6,033 \\
\hline United Kingdom & 11,579 & 24,958 & 11.6 & 0.25 & 46.4 & 61.4 & 62.6 & 40,660 \\
\hline EU 27 & 103,952 & 198,292 & 11.9 & 0.23 & 52.4 & 59.5 & 61.2 & 333,248 \\
\hline EU 25 & 99,211 & 186,057 & 12.0 & 0.22 & 53.3 & 59.4 & 61.2 & 312,985 \\
\hline EU 15 & 84,611 & 155,917 & 12.2 & 0.22 & 54.3 & 59.8 & 61.5 & 261 \\
\hline
\end{tabular}

Definitions and sources of data:

R Retired persons (people over average effective retirement age). Source: calculated by the author from Eurostat data (2007).

E Employed people in full-time equivalents. Source: calculated by the author from Eurostat Labour Force Survey data (2007).

c(\%) Public expenditure (\% of GDP) in old age and survivors pensions. Source: Eurostat ESSPROS database, 2006 data.

t Transfer ratio calculated as in formula (5) in order to ensure equality in equation (1).

EDR Economic Dependency Ratio (number of retired persons by 100 employed people).

ER Employment rate (employed persons by 100 working age population) in full-time equivalents.

ERA Average Effective Retirement Age. Source: Eurostat 2007 data on average exit age from the labour market.

wap Working age population (persons aged 15-64 years old). Source: 2008-based Eurostat demographic projection. 


\section{Different measures to compensate for the impact of ageing}

In a first step, the model examines the impact of ageing, and more specifically the growth of the number of retired people, on the equilibrium between the two sides of the model between 2000 and 2050, all other key factors remaining constant. The exact number of retired people, R', is determined by the value of the effective retirement age (ERA, which in this first step is kept constant between 2008 and 2050) and the variation of the age structure determined by the Eurostat convergence scenario. The model's outputs show the magnitude of the changes needed in the different parameters in order to maintain the model in equilibrium and thereby counteract the effect of ageing. These compensatory changes are examined one by one (approach ceteris paribus) to assess the individual compensatory effect in ageing that each key factor could have. In this paper, the measure of increasing the number of employed persons (E') through immigration (Imm') to compensate for the growth of retired people, will be examined in more detail (Section 6.1). Subsequently, other alternative measures will be analysed more briefly (Section 6.2), for instance:

- Increasing the number of employed persons (E') by raising the employment rates (ER') of the indigenous population (without immigration);

- Increasing the effective retirement age (ERA'): this results in a decrease in the number of retired people $(\mathrm{R})$ and an increase in the number of potential contributors;

- Increasing the share of GDP to finance pensions ( $\left.c^{\prime}\right)$, by increasing social contributions and/or taxes;

- Decreasing the transfer ratio ( $\left.\mathrm{t}^{\prime}\right)$, by making the average pension increase by a smaller percentage than the GDP per employed person (productivity).

In a second step (Section 6.3), different future values of the key factors are also introduced in the model as inputs, resulting in different prospective scenarios due to the combination of changes in the parameters. Finally, Section 6.4 examines how these parameters vary between EU countries, as they reflect, to some extent, the margins of manoeuvre and flexibility that each country has in addressing the impact of ageing. 


\section{Results}

\subsection{Is it possible to counteract ageing through immigration alone?}

Let us suppose that the EU-27 population is closed to migration, as in the zeromigration Eurostat convergence scenario, and that the effective retirement age is fixed in its 2008 value. Then, on top of mortality, the number of retired people between 2008 and 2050 will only be determined by the age structure ageing process. Table 2 shows the number of retired people in 2050 (R') under these conditions and some of the compensatory changes needed in the key factors to counteract the increase in the number of retired people and maintain the model in equilibrium.

Under the assumptions of a constant effective retirement age of 61.2 years, the number of retired people in the whole European Union will pass from 103.9 million in 2004 (Table 1) to 163.8 million in 2050 (Table 2, first column). If the number of employed people does not change (as do parameters $t$ and c, approach ceteris paribus), then the Economic Dependency Ratio in 2050 (EDR') will suffer a dramatic increase: from 52.4 retired people per 100 employed in 2008, it will grow by 30 percentage points to $82.6 \%$ in 2050 , with national values ranging from $54.7 \%$ in Latvia to $101.5 \%$ in Malta!

The most direct measure to keep the model in equilibrium and to fix the Economic Dependency Ratio up to 2050 would be to increase the number of employed people at the same growth rate as R. The resulting number of employees in 2050 is shown in Table 2 as E'. The value for EU-27 is nearly 318 million employed people in full-time equivalents, compared to 198 million in 2008. This means an employment increase of around 120 million or, in relative figures, a $60 \%$ growth from the current value - or, which is the same, an annual employment growth rate of $1.13 \%$. In other words, this is somewhat less than the average employment growth that was required by the EU between 2000 and 2010 in order to fulfil the Lisbon employment targets (estimated at around 1.2\% p.a.), and practically the same growth rate than the one experienced by the EU-27 during the last decade (1997-2007 data, i.e. in a period of economic expansion), except here employment is assumed to keep growing until 2050 (for more than 40 years). Moreover, the resulting 'impossible' employment rate in 2050 $\left(E R^{\prime}=131 \%\right)$ means that the regressive evolution of the working age populationwhich will pass from 333 million in 2008 to 242 million in 2050-will constitute an additional limitation in achieving the required employment level to compensate for ageing. 
Table 2:

Parameters of the model in 2050 when the increase of employment through immigration is the only compensatory action (ceteris paribus approach) EUROSTAT NO-MIGRATION CONVERGENCE SCENARIO

\begin{tabular}{|c|c|c|c|c|c|c|c|}
\hline & \begin{tabular}{|c}
$\mathrm{R}$ (In \\
retirement ag \\
thousands)
\end{tabular} & EDR (\%) & $\begin{array}{c}\text { E' } \\
\text { (Employed, } \\
\text { thousands) }\end{array}$ & Eg' (\%) & $\begin{array}{l}\text { wap (Working } \\
\text { age pop., } \\
\text { thousands) }\end{array}$ & ER' (\%) & $\begin{array}{c}\text { Imm' } \\
\text { (thousands }\end{array}$ \\
\hline Belgium & 3,372 & 85.2 & 6,022 & 1.00 & 5,665 & 106.3 & 1,773 \\
\hline Bulgaria & 1,958 & 60.8 & 4,477 & 0.79 & 3,247 & 137.9 & 2,042 \\
\hline Czech Republic & 3,451 & 71.9 & 7,872 & 1.19 & 4,642 & 169.6 & 4,390 \\
\hline Denmark & 1,702 & 69.2 & 3,541 & 0.87 & 3,082 & 114.9 & 1,230 \\
\hline Germany & 26,000 & 80.0 & 44,385 & 0.75 & 34,077 & 130.3 & 18,828 \\
\hline Estonia & 377 & 60.0 & 906 & 0.87 & 674 & 134.3 & 400 \\
\hline Greece & 3,893 & 89.1 & 6,551 & 0.97 & 4,855 & 134.9 & 2,910 \\
\hline Spain & 16,609 & 87.2 & 35,681 & 1.51 & 20,206 & 176.6 & 20,527 \\
\hline France & 21,922 & 92.4 & 37,160 & 1.07 & 36,878 & 100.8 & 9,502 \\
\hline Ireland & 1,485 & 76.0 & 5,488 & 2.49 & 2,959 & 185.5 & 3,269 \\
\hline Italy & 20,957 & 96.7 & 30,079 & 0.78 & 24,575 & 122.4 & 11,648 \\
\hline Cyprus & 269 & 74.2 & 887 & 2.15 & 448 & 198.0 & 551 \\
\hline Latvia & 593 & 54.7 & 1,495 & 0.77 & 1,038 & 144.0 & 716 \\
\hline Lithuania & 1,044 & 70.8 & 2,218 & 0.98 & 1,637 & 135.5 & 991 \\
\hline Luxembourg & 174 & 93.1 & 344 & 1.46 & 258 & 133.1 & 150 \\
\hline Hungary & 3,144 & 81.5 & 5,457 & 0.83 & 4,545 & 120.1 & 2,048 \\
\hline Malta & 150 & 101.5 & 239 & 1.14 & 2045 & 116.6 & 85 \\
\hline Netherlands & 4,844 & 76.1 & 11,698 & 1.46 & 8,935 & 130.9 & 4,997 \\
\hline Austria & 2,894 & 82.0 & 5,701 & 1.15 & 3,853 & 147.9 & 2,811 \\
\hline Poland & 13,541 & 93.2 & 27,110 & 1.50 & 18,523 & 146.4 & 13,218 \\
\hline Portugal & 3,452 & 72.2 & 7,752 & 1.16 & 4,768 & 162.6 & 4,176 \\
\hline Romania & 5,828 & 64.7 & 15,759 & 1.34 & 10,139 & 155.4 & 8,154 \\
\hline Slovenia & 722 & 77.6 & 1,552 & 1.23 & 869 & 178.7 & 901 \\
\hline Slovakia & 1,970 & 84.6 & 4,608 & 1.64 & 2,631 & 175.1 & 2,634 \\
\hline Finland & 1,616 & 69.9 & 3,358 & 0.89 & 2,883 & 116.5 & 1,195 \\
\hline Sweden & 2,651 & 64.6 & 6,234 & 1.00 & 5,149 & 121.1 & 2,372 \\
\hline United Kingdom & 19,177 & 76.8 & 41,333 & 1.21 & 35,199 & 117.4 & 14,934 \\
\hline EU 27 & 163,796 & 82.6 & 317,908 & 1.13 & 241,941 & 131.4 & 136,452 \\
\hline EU 25 & 156,011 & 83.9 & 297,671 & 1.13 & 228,554 & 130.2 & 126,256 \\
\hline EU 15 & 130,748 & 83.9 & 245,328 & 1.09 & 193,342 & 126.9 & 100,321 \\
\hline
\end{tabular}

Definitions:

R Retired persons (people over average effective retirement age) in 2050 determined by Eurostat nomigration convergence scenario.

EDR Economic Dependency Ratio (number of retired persons by 100 employed people) in 2050 if total employment (in full-time equivalents) does not change.

E' Employed people in full-time equivalents maintaining the model in equilibrium in 2050 .

Eg' Annual employment growth (in \%) between 2008 and 2050 maintaining the model in equilibrium.

wap Working age population (persons aged 15-64 years old) in 2050 determined by Eurostat no-migration convergence scenario.

ER' Employment rate (employed persons / working age population) in full-time equivalents maintaining the model in equilibrium in 2050.

Imm' Number of (employed) immigrants and their descendants maintaining the model in equilibrium in 2050. 
Figure 1 illustrates these numbers, showing the change in the number of retired people determined by the Eurostat no-migration convergence scenario (R) and the number of employed persons maintaining the model in equilibrium (E') for the EU-27 between 2008-2050. These growing numbers are compared with the decreasing size of the working age population (wap). If we consider that an employment rate of $75 \%$ (in full-time equivalents) is a plausible ceiling of employability in the European Union-this is even higher that the level presently existing in the EU country with the highest employment rate, Latvia, at $69.2 \%$ then there will be a deficit in workforce numbers from the year 2020 onwards.

The magnitude of the employment growth required to compensate for ageing is so important that the role of international (extra-EU) immigration is emphasised. Let us estimate the number of required immigrants (including their descendants) as the difference between E' (total employment in full-time equivalents maintaining the system in equilibrium) and a level of $75 \%$ of the working age population projected by the convergence scenario (Figure 1). The workforce deficit will reach its maximum in 2050, when E' will overpass the $75 \%$ of the native working age population by more than 136 million employees. In other words, this will be the number of additional required workers, i.e. extra-EU immigrants (and their descendants) to compensate for ageing. The model obviously assumes all these immigrants and their children to be employed, so the real figure of necessary arriving immigrants would in fact be much higher, as the current employment rate of immigrants with non-EU citizenship is lower than that of EU citizens (European Commission 2009), and the number of immigrants outside the working age should also be taken into account. Moreover, arriving immigrants will eventually enter retirement as well, resulting in an additional increase of $E$ ' to compensate for the growing numbers of $R^{\prime}$ and to keep the model in equilibrium. 
Figure 1:

Changes in the numbers of retired people $(R)$ and working age population (wap) in the EU-27 between 2008 and 2050, as well as in the number of employed persons ( $E$ ') maintaining the model in equilibrium

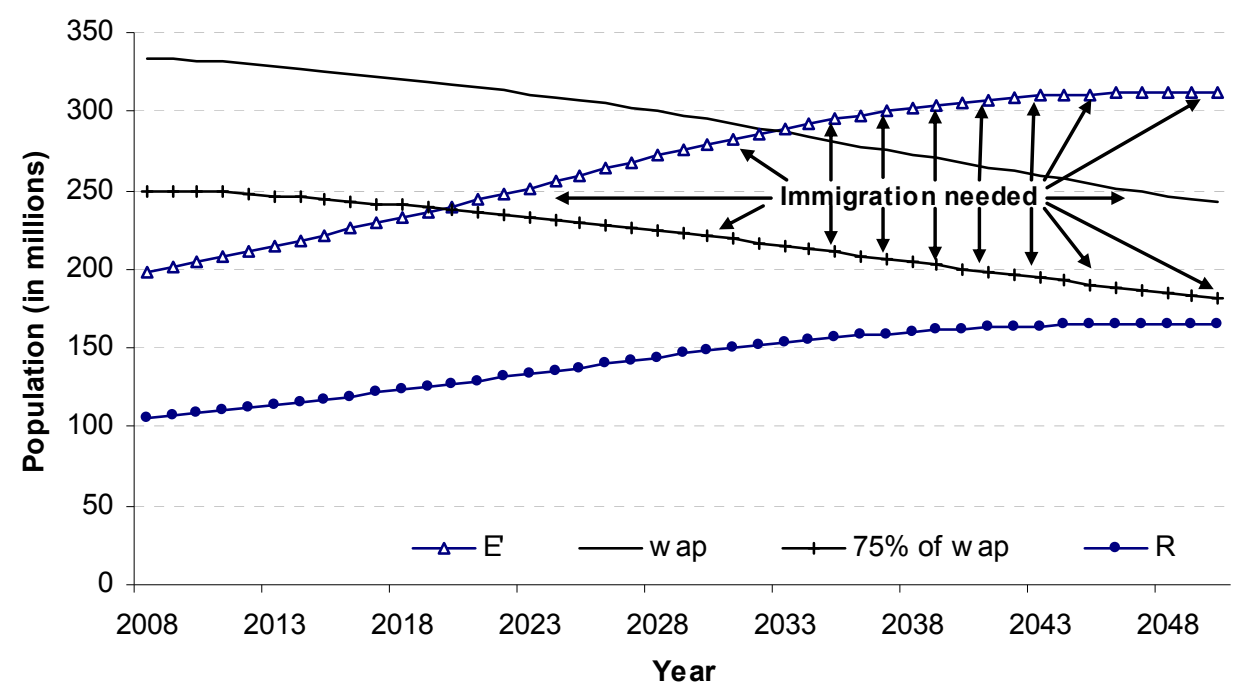

Source: elaborated using Eurostat no-migration convergence scenario.

If we keep the conservative estimation of 136 million employed immigrants (including their employed children) by the year 2050, it means an average entry of more than 3.2 million net migrants per year. To obtain an idea of the magnitude of this inflow, we should bear in mind that the number of immigrants coming to the EU between 2002 and 2008 (period of high immigration) has fluctuated between 1.6 and 2.0 million per year (Eurostat data, net migration including corrections). This result shows that employment growth alone will not be able to counteract ageing at EU level, even if complemented with immigration, as both the amount of new employment required and the level of immigration needed can clearly not be sustained over a period of 42 years.

Results are even more dramatic if we use the more 'realistic' Eurostat convergence scenario with migration (Table 3 ), incorporating a positive net migration of 49.4 million immigrants between 2008 and 2050. In such a case, the number of retired people grows to almost 172 million, but the working age population also reaches 294 million in 2050 . Therefore the required number of employed immigrants (and their children) to compensate for ageing is 'only' 112 million. However, as said above, this scenario already includes a net migration of around 50 million immigrants during the projected period (a 1.2 million average per year), so the total number of required employed immigrants and their descendants under this scenario would really be 160 million. 
Table 3:

Parameters of the model in 2050 when the increase of employment through immigration is the only compensatory action (ceteris paribus approach) EUROSTAT CONVERGENCE SCENARIO (WITH MIGRATION)

\begin{tabular}{|c|c|c|c|c|c|c|c|}
\hline & $\begin{array}{c}\mathrm{R} \text { (In } \\
\text { retirement age, } \\
\text { thousands) }\end{array}$ & $\begin{array}{c}\text { EDR } \\
(\%)\end{array}$ & $\begin{array}{c}\mathrm{E} \\
\text { (Employed } \\
\text { thousands) }\end{array}$ & Eg' (\%) & $\begin{array}{l}\text { wap (Working } \\
\text { age pop., } \\
\text { thousands) }\end{array}$ & ER' (\%) & $\begin{array}{c}\text { Imm' } \\
\text { (thousands) }\end{array}$ \\
\hline Belgium & 3,621 & 91.5 & 6,466 & 1.17 & 7,144 & 90.5 & 1,108 \\
\hline Bulgaria & 1,935 & 60.1 & 4,426 & 0.76 & 3,341 & 132.5 & 1,921 \\
\hline Czech Republic & 3,663 & 76.3 & 8,355 & 1.33 & 5,584 & 149.6 & 4,167 \\
\hline Denmark & 1,722 & 70.0 & 3,582 & 0.90 & 3,493 & 102.6 & 963 \\
\hline Germany & 27 & 82.1 & 45,524 & 0.81 & 41,857 & 108.8 & 14,131 \\
\hline Estonia & 371 & 58.9 & 890 & 0.83 & 686 & 129.7 & 375 \\
\hline Greece & 4,166 & 95.4 & 7,009 & 1.13 & 6,335 & 110.7 & 2,258 \\
\hline Spain & 19 & 99.6 & 40,732 & 1.83 & 29,120 & 139.9 & 18,892 \\
\hline France & 23 & 95.2 & 38,306 & 1.15 & 40,737 & 94.0 & 7,753 \\
\hline Ireland & 1,618 & 82.8 & 5,981 & 2.70 & 3,838 & 155.9 & 3,103 \\
\hline Italy & 24 & 107.9 & 33,572 & 1.05 & 33,727 & 99.5 & 8,277 \\
\hline Cyprus & 315 & 87.0 & 1,040 & 2.54 & 772 & 134.7 & 461 \\
\hline Latvia & 587 & 54.1 & 1,478 & 0.74 & 1,042 & 141.8 & 697 \\
\hline Lithuania & 1,046 & 70.9 & 2,223 & 0.98 & 1,589 & 139.9 & 1,031 \\
\hline Luxembourg & 203 & 108.6 & 401 & 1.84 & 424 & 94.6 & 83 \\
\hline Hungary & 3,305 & 85.7 & 5,736 & 0.95 & 5,232 & 109.6 & 1,812 \\
\hline Malta & 160 & 107.8 & 253 & 1.28 & 242 & 104.6 & 72 \\
\hline Netherlands & 4,723 & 74.2 & 11,406 & 1.40 & 9,879 & 115.5 & 3,997 \\
\hline Austria & 3,035 & 86.0 & 5,979 & 1.26 & 5,322 & 112.4 & 1,988 \\
\hline Poland & 14 & 93.2 & 27,114 & 1.50 & 18,900 & 143.5 & 12,938 \\
\hline Portugal & 3,789 & 79.3 & 8,508 & 1.38 & 6,512 & 130.7 & 3,624 \\
\hline Romania & 5,830 & 64.7 & 15,764 & 1.34 & 10,139 & 155.5 & 8,160 \\
\hline Slovenia & 745 & 80.0 & 1,599 & 1.30 & 1,028 & 155.6 & 828 \\
\hline Slovakia & 2,023 & 86.9 & 4,730 & 1.70 & 2,771 & 170.7 & 2,652 \\
\hline Finland & 1,679 & 72.6 & 3,487 & 0.98 & 3,133 & 111.3 & 1,137 \\
\hline Sweden & 2,781 & 67.8 & 6,540 & 1.12 & 6,294 & 103.9 & 1,819 \\
\hline United Kingdom & 19 & 77.2 & 41,537 & 1.22 & 45,047 & 92.2 & 7,752 \\
\hline EU 27 & 171,744 & 86.6 & 332,640 & 1.24 & 294,188 & 113.1 & 112,00 \\
\hline EU 25 & 163,979 & 88.1 & 312,450 & 1.24 & 280,708 & 111.3 & 101,91 \\
\hline EU 15 & 138,223 & 88.7 & 259,032 & 1.22 & 242,860 & 106.7 & 76,888 \\
\hline
\end{tabular}

Definitions:

R Retired persons (people over average effective retirement age) in 2050 determined by Eurostat convergence scenario (with migration).

EDR Economic Dependency Ratio (number of retired persons by 100 employed people) in 2050 if total employment (in full-time equivalents) does not change.

$\mathbf{E}^{\prime} \quad$ Employed people in full-time equivalents maintaining the model in equilibrium in 2050.

Eg' Annual employment growth (in \%) between 2008 and 2050 maintaining the model in equilibrium.

wap Working age population (persons aged 15-64 years old) in 2050 determined by Eurostat convergence scenario (with migration).

ER Employment rate (employed persons / working age population) in full-time equivalents maintaining the model in equilibrium in 2050 .

Imm' Number of (employed) immigrants and their descendants maintaining the model in equilibrium in 2050. 


\subsection{Alternative measures to counteract ageing}

The Table 4 columns show the alternative compensating changes required in the other parameters of Formula (4) to counteract the sole impact of ageing for the period ending in 2050, as explained in Section 5 (ceteris paribus approach). We have just seen that the first alternative measure-increasing the number of employed persons (E') through an increase in the employment rates (ER') of the indigenous population, without immigration - is not possible given the future reduction of the EU working-age population and the high amount of employment creation required. Therefore, the results of the other alternative measures to compensate for the effects of ageing will be emphasised in this section.

- The average effective retirement age, which is estimated at the age of 61.2 in 2008 at EU-27 level, should increase by more than 10 years until 2050 (to reach a level of 71.4 years, see Column ERA' in Table 4) in order to maintain the model in equilibrium - by fixing the number of retired people at nearly 104 million like in 2008, all other parameters remaining equal. This is, without doubt, a very important increase, but not all that different from the observed growth in life expectancy since 1960 which developed at a pace of two additional years per decade.

- The GDP contribution to pensions (c) should increase from $12 \%$ in 2008 to almost $19 \%$ in 2050 (Column c', Table 4). Therefore, there should be a change of +7 percentage points in 42 years (Column cc), amounting to a $58 \%$ increase across the period studied. This would be a very important growth as the current value for Italy, the country with the highest GDP share to pay for pensions, is $15.5 \%$. However this result is under the assumption that the EU-27 GDP will not grow, which is unsustainable in the long term. Therefore, the effort needed to finance the future pension burden will realistically be lower than that predicted by the model. 
Table 4:

Alternative compensatory actions (ceteris paribus approach) to maintain the model in equilibrium in $\mathbf{2 0 5 0}$

EUROSTAT NO-MIGRATION CONVERGENCE SCENARIO

\begin{tabular}{l|rr|rr|rrrr}
\hline & ERA' & cERA & c' $(\%)$ & cc (\%) & t' & ct & cp (\%) & cGDP/e \\
\hline Belgium & 71.2 & 9.6 & 20.5 & 7.0 & 0.16 & 0.66 & -34.3 & 52.1 \\
Bulgaria & 70.1 & 6.0 & 10.7 & 3.0 & 0.13 & 0.72 & -28.0 & 39.0 \\
Czech Republic & 71.1 & 10.4 & 12.8 & 5.0 & 0.11 & 0.61 & -39.0 & 64.0 \\
Denmark & 69.8 & 9.2 & 15.5 & 4.7 & 0.16 & 0.69 & -30.5 & 43.9 \\
Germany & 69.7 & 7.7 & 16.7 & 4.5 & 0.15 & 0.73 & -26.8 & 36.6 \\
Estonia & 69.0 & 6.5 & 8.1 & 2.5 & 0.09 & 0.69 & -30.6 & 44.0 \\
Greece & 70.8 & 9.8 & 18.1 & 6.0 & 0.14 & 0.67 & -33.3 & 50.0 \\
Spain & 74.8 & 12.7 & 15.8 & 7.4 & 0.10 & 0.53 & -46.6 & 87.4 \\
France & 70.3 & 10.9 & 20.3 & 7.3 & 0.14 & 0.64 & -36.1 & 56.6 \\
Ireland & 78.8 & 14.7 & 13.0 & 8.4 & 0.06 & 0.36 & -64.4 & 180.8 \\
Italy & 70.2 & 9.8 & 21.5 & 6.0 & 0.16 & 0.72 & -27.9 & 38.8 \\
Cyprus & 77.4 & 13.9 & 20.4 & 12.0 & 0.11 & 0.41 & -59.1 & 144.7 \\
Latvia & 68.9 & 5.6 & 7.9 & 2.2 & 0.10 & 0.72 & -27.5 & 38.0 \\
Lithuania & 67.8 & 7.9 & 8.6 & 2.9 & 0.08 & 0.67 & -33.5 & 50.3 \\
Luxembourg & 73.9 & 14.5 & 13.5 & 6.2 & 0.08 & 0.54 & -45.7 & 84.0 \\
Hungary & 67.8 & 8.0 & 13.0 & 3.8 & 0.11 & 0.71 & -29.3 & 41.5 \\
Malta & 69.0 & 10.5 & 15.2 & 5.8 & 0.09 & 0.62 & -37.9 & 61.1 \\
Netherlands & 76.3 & 12.4 & 20.9 & 9.5 & 0.15 & 0.54 & -45.6 & 83.9 \\
Austria & 72.3 & 11.4 & 21.7 & 8.3 & 0.16 & 0.62 & -38.1 & 61.6 \\
Poland & 70.9 & 11.6 & 21.5 & 10.0 & 0.12 & 0.54 & -46.4 & 86.6 \\
Portugal & 72.7 & 10.1 & 19.0 & 7.3 & 0.16 & 0.62 & -38.3 & 62.2 \\
Romania & 73.3 & 9.0 & 10.8 & 4.6 & 0.10 & 0.57 & -42.8 & 74.8 \\
Slovenia & 71.3 & 11.5 & 16.8 & 6.7 & 0.13 & 0.60 & -40.1 & 66.8 \\
Slovakia & 71.5 & 12.8 & 13.7 & 6.8 & 0.08 & 0.51 & -49.5 & 97.9 \\
Finland & 69.9 & 8.3 & 13.9 & 4.3 & 0.14 & 0.69 & -31.1 & 45.2 \\
Sweden & 72.8 & 8.9 & 18.3 & 6.3 & 0.19 & 0.66 & -34.2 & 51.9 \\
United Kingdom & 73.0 & 10.4 & 19.2 & 7.6 & 0.15 & 0.60 & -39.6 & 65.6 \\
\hline EU 27 & 71.4 & 10.2 & 18.8 & 6.9 & 0.14 & 0.63 & -36.5 & 57.6 \\
EU 25 & 71.5 & 10.3 & 18.9 & 6.9 & 0.14 & 0.64 & -36.4 & 57.3 \\
EU 15 & 71.8 & 10.3 & 18.8 & 6.6 & 0.14 & 0.65 & -35.3 & 54.5 \\
\hline Defintiny & & & & & & & &
\end{tabular}

Definitions:

ERA' Average Effective Retirement Age in 2050 maintaining the model in equilibrium.

cERA Increase in years in the average Effective Retirement Age between 2004 and 2050 maintaining the model in equilibrium.

C' (\%) Public expenditure (\% of GDP) in old age and survivors pensions in 2050 maintaining the model in equilibrium.

cc (\%) Increase (in \% points) in public expenditure in old age and survivors pensions in 2050 maintaining the model in equilibrium.

t:̈ Transfer ratio in 2050 maintaining the model in equilibrium.

ct Coefficient multiplying 2008 Transfer ratios maintaining the model in equilibrium in 2050

cp \% change in average pension between 2008 and 2050 maintaining the model in equilibrium (if productivity remains constant).

cGDP/e (\%) \% change in GDP per employee (productivity) between 2008 and 2050 maintaining the model in equilibrium (if average pension remains constant). 
- Finally, the transfer ratio ( $\mathrm{t}$ ) should be multiplied by 0.63 (Coefficient ct, Table 4), that is, decreasing the average pension by $37 \%$ (Column $\mathrm{cp}$ ) in relation to the GDP per employee. Or in other words, increasing productivity by $58 \%$ in the same period - which means an average growth of $1.1 \%$ per year-if pensions remain constant (Column cGDP/e). That means making productivity grow quicker than absolute pension levels between 2008 and 2050. An annual GDP growth of $1.1 \%$ is feasible as it has been reached in the past (e.g. it has been surpassed every year at EU-27 level during the period 1999-2007). However, it should also be kept in mind that the growth needed will probably be even higher because pensions are also likely to increase in the future. ${ }^{8}$

These compensatory changes have been estimated using the Eurostat no-migration convergence scenario, but results are similar to those obtained when using the scenario with migration, which are not presented here. ${ }^{9}$

The changes required to ensure the equilibrium of the model obviously have to be seen as extreme values, since the real evolutions are likely to be a mix of changes in all the factors. For instance, given the measures already taken in most EU countries to limit pension growth which will lead, if unchanged, to a decrease in the relative pension levels and an increase in the effective retirement age, a future decrease in transfer ratios and a growth of ERA should be taken for granted.

\subsection{The compensatory impact of changes in key parameters}

In the second phase of the analysis, the parameters of Equation 4 have been first modified and then combined, to check the feasibility of the measures compensating ageing. Though only the results obtained for whole EU-27 with the model using the no-migration scenario are presented, the exercise has been done for both Eurostat convergence scenarios and for all the EU countries.

For instance, increasing the number of people in employment (E) up to a realistic annual employment growth of $0.6 \%$ during the studied period would result in the EDR' moderately increasing up to 64.5 retired people per 100 employed persons, although the resulting employment rate, $105 \%$, means that the

8 This is not the place to discuss the future evolution of pensions, however it should be mentioned that their future growth could be mitigated at EU level through indexing pensions to prices (as it is done, for instance, in Spain) rather than to wages, which is currently the case in many other European countries. By doing this, the transfer ratio should decrease (as average pension would probably grow less, over the long term, than the GDP per employee) and the sustainability of pension systems could be more easily achieved.

9 Changes required are actually slightly more important, as the number of retired people in the scenario with migration is also larger. For instance, the average effective retirement age should increase up to 71.8 instead of 71.4 at EU level to maintain the model in equilibrium; public expenditure in pension should increase $7.8 \%$ points instead of 6.9 ; transfer ratio should be multiplied times 0.61 instead of times 0.63 , etc. But, in my opinion, these tiny differences do not justify adding an additional table when the main findings are the same as those obtained with the no-migration scenario. 
number of jobs required to compensate for ageing in 2050 is still larger than the projected working-age population. A lower annual employment growth of $0.3 \%$ would result in a more feasible (but still too high) employment rate of $93 \%$ in 2050, combined with an EDR' of 73.5 (currently being of 52.4). What the model shows is that increasing employment is an important measure to counteract ageing, but the size of the potential workforce (the working age population) limits the capacity of growth of the number of people in employment. Therefore, it has to be combined with additional measures like an increase in the age at which people exit the labour market.

If we consider increasing the effective retirement age (ERA) alone-e.g. delaying it from the current 61.2 years to 65 in $2050-\mathrm{R}$ would drop from 164 to 143 million and the EDR' would move from its present level of 52.4 retired per 100 employed, to 72.3. This is still an important level, but much lower than the resulting 83.4 if the average exit age remains unchanged. The EDR' would improve much more $(57.3 \%)$ if the ERA was delayed up to 70 years, with only 113 million retirees in 2050. However, we must recognise that, even in a context of growing life expectancy, such a significant delay in the retirement age is not easy to obtain.

It would seem more realistic to combine different measures in order to counteract ageing: for instance, employment growth with a delaying retirement age. Indeed, the higher the increase in effective retirement age, the lower the employment growth needed to maintain equilibrium. Or the other way around, the higher the growth in employment, the lower the increase in effective retirement age needed to compensate for ageing. If an average $0.3 \%$ employment growth p.a. is combined with a delay in the ERA of 5 years, until the age of 66, then R and E would result, respectively, in 137 million and 225 million people in 2050, with a resulting EDR' of $61 \%$, which seems a plausible level-EDR is currently even higher in Italy and Malta, see Table 1 . The resulting employment rate in full-time equivalents, $93 \%$, is still too high, but the deficit in workforce numbers can be compensated for with a realistic level of immigration: around 1.8 million additional immigrants per year between 2004 and 2050, which is a level similar to that observed in the EU-27 during the first decade of the 21st century. This level of immigration could be reduced even more, down to slightly over 550,000 net migrants per year (Figure 2), if the aforementioned measures were combined with an increase in the GDP contribution to pensions (c), which would pass from the current $12 \%$ to $15 \%$ in 2050 at EU-27 level (about equal to the current level in Italy, $15.5 \%$ ). Moreover, the required level of immigrants could even be reduced to zero if these measures were combined with an additional decrease of $13 \%$ in the transfer ratio-i.e. through a feasible increase of productivity (GDP/employee) of $15 \%$ over a period of 42 years (if average pensions remain constant) or a reduction of the average pension in $13 \%$ if productivity remains stable. Or through a more simplistic - but harder to achieve-combination of a growth in retirement age up to 66 with an increase in c until 18\% (see Figure 3). 
Figure 2:

Parameter changes if employment grows by $0.3 \%$ p.a., the ERA increases by 5 years and ' $c$ ' reaches a level of $15 \%$. EU-27, 2008-2050

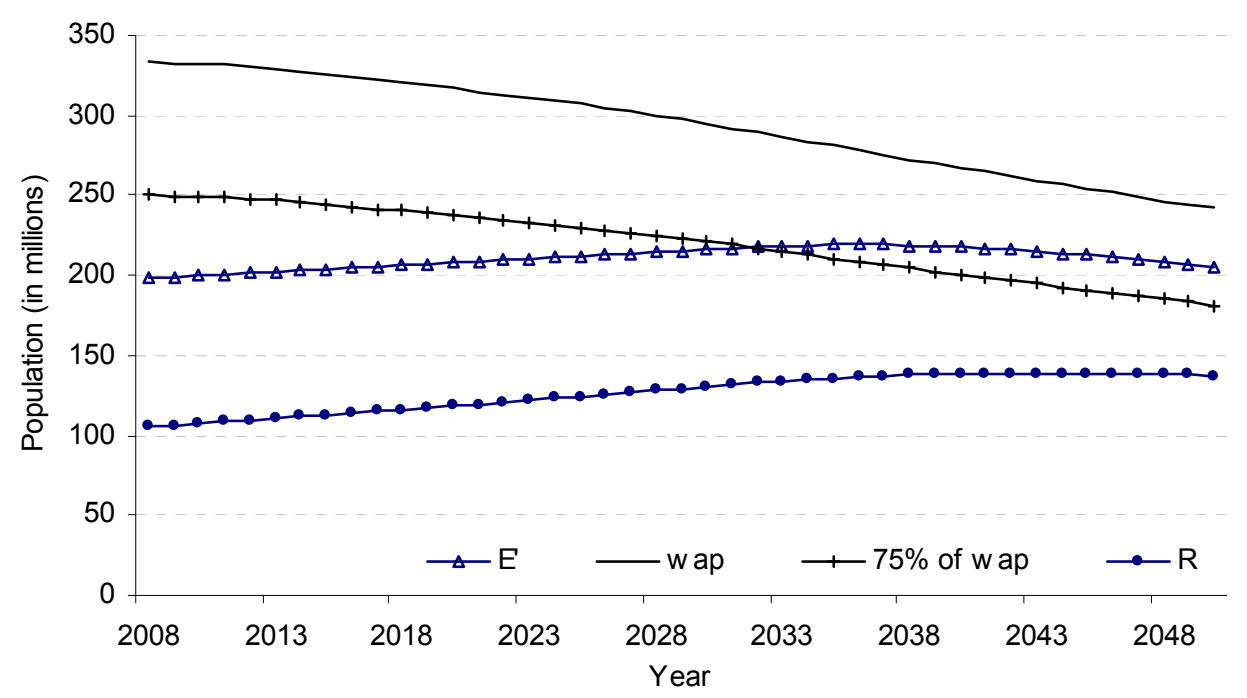

Source: elaborated using Eurostat no-migration convergence scenario.

Figure 3:

Parameter changes if the effective retirement age increases by 5 years and ' $c$ ' reaches a level of $18 \%$. EU-27, 2008-2050

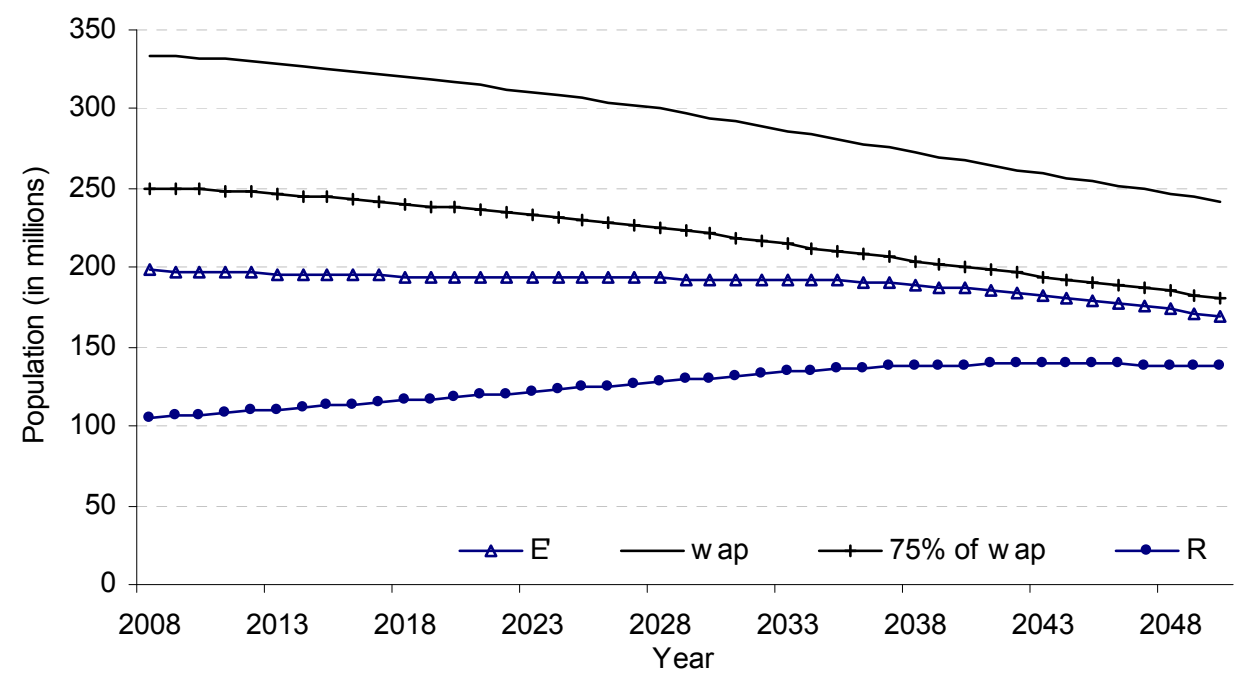

Source: elaborated using Eurostat no-migration convergence scenario. 
The model's results demonstrate that the long-term sustainability of pension systems appears to be a challenge which can only be overcome if the European Union achieves high, but nonetheless feasible, levels of employment growth over the next decades, combined with other complementary measures like increasing the average labour market exit age and the GDP share devoted to pensions, and reducing the ratio of the average pension to productivity. Immigration will only be needed to compensate for ageing if some of these measures are either not implemented at all or not effective enough. Indeed, the model's results highlight that immigration alone is not the solution to maintain the model at equilibrium, but only a complementary measure. However, owing to differences between the ageing process and other relevant factors across EU countries, some compensatory measures might be more appropriate for some countries than others.

\subsection{Considerations at a national level}

As the model does not take on board the particular features of each national pension system, its outcomes at a national level must be interpreted with more caution. These are the main findings:

- None of the countries of Europe can expect to escape the ageing population trend. The 'baby boomers' will reach their retirement age and, despite national differences in fertility rates, the younger cohorts entering the labour market will be unable to compensate for the high numbers of older people entering retirement age.

- However, the common trend towards ageing will present important timing and intensity differences among EU countries. Table 2 shows the national impact of ageing, if all other factors, including current employment rates, remain unchanged. Though Ireland and Cyprus - which currently have the youngest populations and the lowest economic dependency ratios-will face the highest pressure to compensate for the impact of ageing (see Columns Eg and ER' in Table 2), the highest dependency ratios (EDR') in 2050 will be found in Malta, Italy, Poland and France, all of them countries which are currently characterised by both relatively low employment rates and retirement ages. By contrast, the three Baltic States, the Scandinavian countries, Bulgaria and Romania will be the least affected by dependency changes between 2008 and 2050 .

- Differences in the ageing process between the EU countries will clearly condition the appropriate policy options for counteracting it. In addition, there already are significant differences in the current levels of various parameters of the model (Table 1 shows the actual values for some of the relevant key factors at a national level). Therefore, measures to preserve the model's equilibrium will not have the same impact in each European country.

- Apart from their potential impact, some measures are difficult to apply in some countries, due to the current value of the parameters, but a lot more 
appropriate for others (see Table 2). In countries like Romania, Bulgaria, Ireland, Sweden and Cyprus, where the effective retirement age (ERA) is already late even today, any additional increase in the average effective retirement age could be more difficult to implement than in other countries like Malta, Slovakia, Luxembourg or France where the exit of the labour market is, on average, at much younger ages; hence, other measures may have to be taken in the former group of countries.

- Similarly, in countries with current high employment rates (ER) like Latvia, Estonia, Denmark or Sweden, it seems more difficult to consider job creation as the key compensatory measure than in Malta, Poland, Italy, Hungary or Belgium with their low employment levels. While a decrease in the transfer ratio could have significant stabilising effects in some countries (for instance in Sweden, Austria, the UK and Belgium, where the present pension level in relation to GDP per employee presents some margins for manoeuvre), the current lower share of GDP devoted to pensions in Ireland, the Baltic countries or Romania, shows that an increase in ' $c$ ' is a more plausible measure for these countries to maintain equilibrium.

- Finally, an additional-and complementary-means to stabilise the system may be to increase the number of employed people through immigration, particularly in those EU countries like Spain or Italy, where the margins of manoeuvre of other measures are already rather tight due to the intensity of ageing.

\section{Conclusions}

The model shows that the impact of ageing on the sustainability of pension systems over the next 42 years is significant at EU level and for the 27 Member States. This challenge can be overcome through a combination of different policies regarding immigration, employment, retirement age, economic productivity and pension levels. A policy framework promoting economic growth with increasing productivity and more jobs for both indigenous people and immigrants (which will be needed if the European working-age population cannot cope with growing employment levels) is therefore required, together with policies encouraging people to remain in work longer-and subsequently improving older worker employability (OECD 2006). Therefore, early exits from the labour market should not continue to be as frequent as they are today. These issues have been assumed by European policymakers, and there is presently a significant pressure across the European Union to implement policies increasing employment and labour market participation levels, encouraging internal migration (free movement of workers), and delaying the actual retirement agemeasures which should help financing future pensions. However, a European consensus regarding the role international immigration is more difficult to 
achieve, as this is a very delicate issue in most EU Member States, with a lot of social and political implications. The model nevertheless demonstrates that, if the entry flow is combined with some of the other policies already mentioned, the number of (employed) immigrants - and their descendants-required in the European Union to counter the effect of ageing on pensions will be similar to, or even lower than, present figures. This policy mix is probably the best way of assuming the varying social costs of the different policy options, as policies will only require small changes. However, if only one policy option is implemented, its social impact could be more difficult to be taken on by stakeholders and the population in general.

The model shows the existence of a wide range of national situations in terms of the appropriate policy measures required in each Member State to maintain the pension system in equilibrium. This is both due to differences in the timing and intensity of the ageing process and to the diverse initial levels of the main factors affecting pension sustainability across EU countries: effective retirement age, employment rates, relative pension level, and GDP share devoted to finance pensions.

Therefore the pension challenge is different for each European country. Those with a high average effective retirement age and high employment rates may need to adjust the GDP contribution and pension levels in order to compensate for the ageing impact. Their margins of manoeuvre appear somewhat smaller than in other countries with lower labour market participation and earlier exit from working activity: these appear to have more scope for adjustments by increasing the average effective retirement age and the employment rates. Finally, immigration seems a complementary resource when all the other compensatory measures are difficult to implement or of insufficient effectiveness due to the magnitude of ageing. Nevertheless, immigration by itself cannot counteract ageing in the European Union as the number of immigrants needed to compensate for the increasing number of retired people would be so high that no country could assume the social and political costs of such a process.

\section{References}

Bijak, J., D. Kupiszewska, M. Kupiskewski, K. Saczuk, and A. Kicinger. 2007. "Population and labour force projections for 27 European countries, 2002-2052: impact of international migration on population ageing." European Journal of Population 23(1): 1-31.

Calot, G. (ed.) 1995. Le vieillissement démographique dans l'Union Européenne à l'horizon 2050. Étude d'impact du viellissement démographique. Directorate-General Employment and Social Affairs, European Commission.

Coleman, D. A. 1992. "Does Europe Need Immigrants? Population and Work Force Projections." International Migration Review 26(2): 413-461. 
Coleman, D. A. 2004. "Europe at the cross-roads - Must Europe's population and workforce depend on new migration?" In: V. Ionsev (ed.) International migration: $I C P D+10$, scientific series "International migration of population: Russia and contemporary world.” Moskow, Max, vol. 12, pp. 19-33.

European Commission. 1997. "Ageing and fiscal policies in the European Union." European Economy, No. 4, The Welfare State in Europe - Challenges and reforms, Luxembourg, OPOCE, pp. 239-388.

European Commission. 2006. The demographic future of Europe - From challenge to opportunity, $\operatorname{COM}(2006) 571$.

European Commission. 2009. Demography Report 2008: Meeting Social Needs in an Ageing Society. Commission Staff Working Document, D.G. for Employment, Social Affairs and Equal Opportunities, E.1 Unit, pp. 255.

Feld, S. 2000. "Active Population Growth and Immigration Hypotheses in Western Europe." European Journal of Population 16: 3-40.

Fotakis, C. 2000. "Demographic ageing, employment growth and pensions sustainability in the EU: the option of Migration." Expert group meeting on Policy Responses to population ageing and population decline, 16-18 October 2000, New York, United Nations.

Fotakis, C. and F. Gil Alonso. 2002. "Le marché européen de l'emploi sous l'angle de l'évolution démographique." Jeunesses, vieillesses, démographies et sociétés. Louvain-la-Neuve, Académia - Bruylant / L'Harmattan, pp. 43-60.

Franco, D. and T. Munzi. 1996. "Public pension expenditure prospects in the European Union: A survey of national projections." European Economy, No. 3, Ageing and Pension expenditure prospects in the Western World. Luxembourg, OPOCE, pp. $1-126$.

Gaymu, J., P. Ekamper, and G. Beets. 2007. “Qui prendra en charge les Européens âgés dépendants en 2030?” Population-F 62(4): 789-822.

Gil Alonso, F. and A. Math. 2000. "Pension Sustainability, Ageing and Labour Supply." Internal working paper No. 2, DG Employment and Social Affairs, European Commission.

Gil Alonso, F. 2005. "Building a simplified model to assess the impact of population ageing, employment trends and immigration levels on pension sustainability in the EU-25 Member States." Paper for the IUSSP International Population Conference 2005, Tours, France, 18-23 July 2005.

Lee, R. D., A. Mason, et al. 2001. "Saving, Wealth, and Population.” In: N. Birdsall, A. C. Kelley, and S. W. Sinding. Population Does Matter: Demography, Poverty, and Economic Growth. Oxford, Oxford University Press, pp. 137-164.

Lesthaeghe, R. 2002. "Europe's demographic issues: fertility, household formation and replacement migration." Population Bulletin of the United Nations. Special issue. Policy Responses to Population Ageing and Decline 44-45: 385-423.

Lutz, W., W. C. Sanderson, and S. Scherbov. (ed.) 2004. The End of World Population Growth in the $21^{\text {st }}$ Century. New Challenges for Human Capital Formation and Sustainable Development. IIASA/Earthscan, London and Sterling, pp. 341.

Lutz, W. and S. Scherbov. 2005. "Will population ageing necessarily lead to an increase in the number of persons with disabilities? Alternative Scenarios for the European Union." Vienna Yearbook of Population Research 2005: 219-234. 
Mason, A. 2005. Demographic Transition and Demographic Dividends in Developed and Developing Countries, United Nations Expert Group Meeting on Social and Economic Implications of Changing Population Äge Structures, Mexico City.

Murphy, M., P. Martikainen, and S. Pennec. 2006. "Demographic Change and the Supply of Potential Family Supporters in Britain, Finland and France in the Period 19112050." European Journal of Population 22(3): 219-240.

OECD. 2006. Live Longer, Work Longer. OECD Publishing, pp. 146.

OECD. 2007a. Ageing and the Public Service. Human Resource Challenges. OECD Publishing, pp. 260.

OECD. 2007b. OECD Pensions at a Glance 2007. Public Policies across OECD countries. OECD Publishing, pp. 204.

OECD. 2009a. OECD Private Pensions Outlook 2008. OECD Publishing, pp. 310.

OECD. 2009b. OECD Pensions at a Glance 2009. Retirement-Income Systems in OECD countries. OECD Publishing, pp. 280.

Prskawetz, A. et al. 2005. Demographic Debate: "Will Population Ageing Decrease Productivity?" Vienna Yearbook of Population Research 2005: 1-15.

Prskawetz, A, D. E. Bloom, and W. Lutz (ed.) 2008. "Population Aging, Human Capital Accumulation, and Productivity Growth." Population and Development Review, a supplement to Vol. 34, pp. 326.

Skirbekk, V. 2004. "Age and individual productivity: a literature survey." Vienna Yearbook of Population Research 2004: 133-153.

United Nations. 2001. Replacement Migration. Is it a solution to declining and ageing populations? New York, UN Population Division, Department of Economic and Social Affairs.

Whitehouse, E. 2007. Pension Panorama. Retirement-Income Systems in 53 Countries. The World Bank, pp. 204. 

